I N S T I T U T O

$\mathrm{DE}$

M E D I C I N A

T R O P I C A L

$\mathrm{DE}$

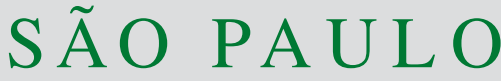

JOURNAL OF THE SÃO PAULO INSTITUTE OF TROPICAL MEDICINE

'Universidade do Estado do Rio de Janeiro, Centro Biomédico, Faculdade de Ciências Médicas, Departamento de Microbiologia, Imunologia e Parasitologia, Laboratório de Helmintologia Romero Lascasas Porto, Rio de Janeiro, Rio de Janeiro, Brazil

${ }^{2}$ Instituto Oswaldo Cruz, Fundação Oswaldo Cruz, Instituto Oswaldo Cruz, Laboratório de Referência Nacional em Hidatidose, Laboratório de Helmintos Parasitos de Vertebrados, Manguinhos, Rio de Janeiro, Brazil

${ }^{3}$ Instituto Federal do Mato Grosso do Sul, Campo Grande, Mato Grosso do Sul, Brazil

${ }^{4}$ Instituto Federal do Acre, Xapuri, Acre, Brazil

${ }^{5}$ Instituto Oswaldo Cruz, Fundação Oswaldo Cruz, Laboratório de Biologia e Parasitologia de Mamíferos Silvestres Reservatórios, Manguinhos, Rio de Janeiro, Brazil

Correspondence to: Rosângela Rodrigues e Silva

Instituto Oswaldo Cruz, Fundação

Oswaldo Cruz, Instituto Oswaldo Cruz,

Laboratório de Referência Nacional em

Hidatidose, Laboratório de Helmintos

Parasitos de Vertebrados, Av. Brasil, 4365,

CEP 21040-360, Rio de Janeiro, RJ, Brazil

Tel: +552125621463

E-mail: rsilva@ioc.fiocruz.br

Received: 11 April 2021

Accepted: 22 June 2021

\section{Spurious infection by Calodium hepaticum (Bancroft, 1983) Moravec, 1982 and intestinal parasites in forest reserve dwellers in Western Brazilian Amazon}

\author{
Fernanda Bittencourt de Oliveira ${ }^{\circledR 1,2}$, Tuan Pedro Dias Correia ${ }^{\circledR 2}$, Leandro \\ Batista das Neves ${ }^{\circledR 2}$, Paulo Eduardo Ferlini Teixeira ${ }^{\left({ }^{3}\right.}$, Junior da Costa \\ Moreira ${ }^{(1)}$, Leandro Siqueira de Souza ${ }^{\circledR 5}$, Renata Heisler Neves ${ }^{\circledR 1}$, \\ Fernanda Barbosa de Almeida ${ }^{(2}$, Márcio Neves Bóia ${ }^{\circledR}$, Rosângela \\ Rodrigues e Silva ${ }^{\left({ }^{2}\right.}$, José Roberto Machado e Silva ${ }^{\left({ }^{1}\right.}$
}

\section{ABSTRACT}

Subsistence hunting is the main source of protein for forest reserve dwellers, contributing to the development of spurious infections by Calodium hepaticum, frequently associated with the consumption of the liver from wild mammals. The prevalence of infections by soil-transmitted helminths (STHs) and intestinal protozoa is considered an indicator of the social vulnerability of a country, besides providing information on habits, customs and quality of life of a given population. Intestinal parasites mostly affect poor rural communities with limited access to clean water and adequate sanitation. This study reports the results of a parasitological survey carried out in 2017 and 2019, in two municipalities (Xapuri and Sena Madureira) in Acre State. Stool samples were collected from 276 inhabitants. Upon receipt, each sample was divided into two aliquots. Fresh samples without preservative were processed and examined by the Kato-Katz technique. Samples fixed in $10 \%$ formalin were processed by the spontaneous sedimentation and the centrifugal sedimentation techniques. Calodium hepaticum eggs were found in three stool samples. The overall STH prevalence was $44.9 \%$. The hookworm prevalence (19.2\%) was higher than that of Ascaris lumbricoides (2.5\%) and Trichuris trichiura $(0.7 \%)$, an unexpected finding for municipalities belonging to the Western Brazilian Amazon. When considering parasites transmitted via the fecal-oral route, Endolimax nana and Entamoeba coli showed the highest positivity rates, of $13 \%$ and $10.9 \%$, respectively. This study is the first report of spurious infection by $C$. hepaticum among forest reserve dwellers that consume undercooked liver of lowland pacas. Additionally, this is the first report of Blastocystis sp. in Acre State.

KEYWORDS: Intestinal parasites. Spurious infection. Calodium hepaticum. Forest reserve. Acre. Brazil.

\section{INTRODUCTION}

Calodium hepaticum (Bancroft, 1983) Moravec, 1982, (syn. Capillaria hepatica) is a zoonotic nematode present in a wide range of mammal hosts (rodents, lagomorphs, canids, ruminants, non-human primates and humans), as well as birds and fish, but rodents are the main hosts ${ }^{1}$. The parasite has a direct life cycle (monoxenous). Upon ingestion of embryonated eggs by natural hosts, L1 larvae hatch in the cecum, penetrate the intestinal wall and migrate to the liver, where they develop into mature worms. Within the hepatic tissue, fertilized adult 
females release non-embryonated eggs and $\mathrm{die}^{2}$. An obvious question is how $C$. hepaticum propagates in the life cycle. There are apparently two main mechanisms: disintegrated carcasses of dead hosts allow non-embryonated eggs to reach the external environment; and through a predator-prey relationship, non-embryonated eggs are excreted along with the host feces into the environment. Under favorable conditions (oxygen, moisture and temperature), the L1 larva develops within the egg to an infective stage that will sustain its life cycle ${ }^{3}$.

Humans acquire infection by two mechanisms: by ingesting embryonated eggs from contaminated environments, whereby humans develop a rare and often fatal liver disease, also reported as the true infection ${ }^{2}$, and by eating raw or undercooked livers from wild hosts, where eggs pass along the gastrointestinal tract and are expelled in the fecal material (spurious infection) ${ }^{4-6}$. To date, 138 cases of spurious infections have been reported in the literature ${ }^{7}$. Out of them, 93 occurred in Brazil $1^{4-6,8-14}$ (Table 1), suggesting that $C$. hepaticum is a foodborne parasite in this country.

Table 1 - Calodium hepaticum spurious infections according to the number of cases, the State and year of notification of cases in Brazil.

\begin{tabular}{lcc}
\hline Articles & $\mathrm{N}$ & State \\
\hline Coimbra Jr. and Mello & 02 & Rondonia \\
Santos et al. ${ }^{9}$ & 01 & Rondonia \\
Santos et al. ${ }^{10}$ & 03 & Mato Grosso do Sul \\
Machado et al. ${ }^{11}$ & 02 & Minas Gerais \\
Carvalho-Costa et al. ${ }^{4}$ & 01 & Amazonas \\
Palhano-Silva et al. ${ }^{12}$ & 27 & Rondonia \\
Camargo et al. ${ }^{13}$ & 02 & Rondonia \\
Soares et al. ${ }^{5}$ & 41 & Mato Grosso \\
Gonçalves et al. ${ }^{6}$ & 09 & Amazonas \\
Klisiowicz et al. ${ }^{14}$ & 05 & Parana \\
\hline Total of articles: 10 & 93 & Total of States: 6 \\
\hline
\end{tabular}

In Acre State, forest reserve dwellers hunt game as a major subsistence strategy for protein consumption. These prey includes red brocket deer (Mazama americana), whitelipped peccary (Tayassu pecari) and lowland or spotted paca (Cuniculus paca $)^{15}$. It is well-recognized that these animals are natural hosts of $C$. hepaticum in Brazilian biomes ${ }^{6,14}$. Previously, we reported the finding of $C$. hepaticum eggs in liver tissues from a free-ranging paca trapped in the Bujari permanent preservation area in Acre $^{16}(0984905000 \mathrm{~S}$, $6785700800 \mathrm{~W}$ ). However, it remains to be determined if people eating undercooked or raw livers were subjected to spurious infections in the state.
Soil-transmitted helminth (STH) infections are considered indicators of the social vulnerability of a country, in addition to providing information on habits, customs, and quality of life of a given population. STHs and pathogenic intestinal protozoa mostly affect poor rural communities with limited access to clean water and adequate sanitation ${ }^{17}$. In this epidemiological scenario, school-aged children and adolescents are especially vulnerable to STH infections, causing significant physical, nutritional and cognitive impairment ${ }^{17}$. Forest dwellers typically practice open defecation on the ground near their homes and have no access to clean water. These conditions give rise to their exposure to intestinal parasites (STHs and protozoa), acquired via the fecal-oral route or skin penetration.

Here we report a parasitological survey in forest reserve dwellers from two municipalities (Xapuri and Sena Madureira) in Acre State. In addition, the sociodemographic characteristics of participating households were evaluated. Our findings, for the first time, provide evidence of spurious infection by $C$. hepaticum in forest reserve dwellers in Acre. The occurrence of intestinal protozoa and STHs is also discussed.

\section{MATERIALS AND METHODS}

\section{Ethics approval and consent to participate}

The study was approved by the Oswaldo Cruz Foundation's Research Ethics Committee (CAAE, $\mathrm{N}^{\circ}$ 38091514.6.0000.5248). Written informed consent was obtained from all adult participants and parents or legal guardians of minors.

\section{Study area and population}

For the past 15 years, we have carried out a research program designed to investigate human and animal polycystic echinococcosis in municipalities located in Acre (AC). This State $\left(09^{\circ} 03^{\prime} \mathrm{S} ; 68^{\circ} 39^{\prime} \mathrm{W}\right)$ is located in the Western Brazilian Amazon, bordering the countries Peru (West) and Bolivia (South), the Amazonas State (North) and the Rondonia State (East).

The survey reported here was performed in 2017 and 2019 in rural communities located within two extractive reserves (RESEX): Seringal Boa Vista $\left(10^{\circ} 18^{\prime} 57.88^{\prime \prime} S\right.$; $68^{\circ} 43^{\prime} 19.83^{\prime}$ 'W) in the Chico Mendes Extractive Reserve, and Cuidado $\left(9^{\circ} 09^{\prime} 12^{\prime \prime} \mathrm{S} 69^{\circ} 02^{\prime} 01^{\prime \prime} \mathrm{W}\right)$, in the CazumbaIracema Extractive Reserve. These communities are located in the municipalities of Xapuri and Sena Madureira, respectively. Xapuri and Sena Madureira are situated $188 \mathrm{~km}$ and $145 \mathrm{~km}$ from the State capital, Rio Branco. 
The residents of extractive reserves live in the Amazon rainforest. Similar to other rural counties located in Acre ${ }^{18,19}$, Xapuri and Sena Madureira have poor environmental indicators. The dwellings are exclusively wooden, lacking appropriate sanitation. Residents practice open defecation on the ground near their homes. In addition, residents have no access to clean water, which is supplied directly from a well located a few meters from their houses ${ }^{19}$.

\section{Study participants and laboratory procedures}

During home visits in Seringal Boa Vista and Cuidado, after explaining the aims of the study to residents, a single stool sample was obtained in an empty plastic container provided for this purpose. Upon receipt, each fecal sample was divided into two aliquots. One aliquot was analyzed without preservative, and another was preserved in $10 \%$ formalin for later examination. Stool samples were examined microscopically for the presence of eggs, larvae and protozoan cysts, using the techniques of spontaneous sedimentation ${ }^{20}$ and centrifugal sedimentation ${ }^{21}$. Fresh unpreserved stool samples were examined by the KatoKatz thick-smear technique ${ }^{22}$, using the commercial Helm Test $^{\circledR}$ (Bio-Manguinhos/Fiocruz, Rio de Janeiro, Brazil), according to the manufacturer's specifications. Each stool sample was used to prepare a microscope slide and examined with an Eclipse E-200 optical microscope (Nikon, Japan) equipped with a Nikon DS-Fi1 digital camera
(Nikon, China) and processed with the NIS-Elements AR 3.0 image analysis software (Nikon, USA).

A structured questionnaire was administered in person to collect data from the participants, containing questions regarding demographics (place of birth, gender, age, educational status, monthly household income), social and family aspects (marital status, number of children, dog ownership, hunting activity, meat eating habits, household sanitation conditions and source of drinking water).

\section{Statistical analysis}

Statistical analyses were performed using the GraphPad Instat version 3.01 (GraphPad Inc., USA). Associations between the positivity of each parasite and the variables age, gender, monoparasitism and polyparasitism were investigated using the Fisher's exact test. Statistical significance was set at $\mathrm{P}<0.05$ and $P$ values $<0.01$ were considered highly significant.

\section{RESULTS}

As shown in Table 2, there was almost equality of males $(53.3 \%$ ( and females $(46.7 \%)$. The prevalence of monoparasitism (71.77\%) compared to polyparasitism $(28.23 \%)$ was extremely significant $(P<0.0001)$, while no significant difference according to gender was found $(P=0.2751)$. When considering parasites transmitted via the fecal-oral route, Endolimax nana (13\%) (36/276) showed

Table 2 - Prevalence of intestinal parasites according to age groups and gender in forest reserve dwellers in Acre State, Western Brazilian Amazon.

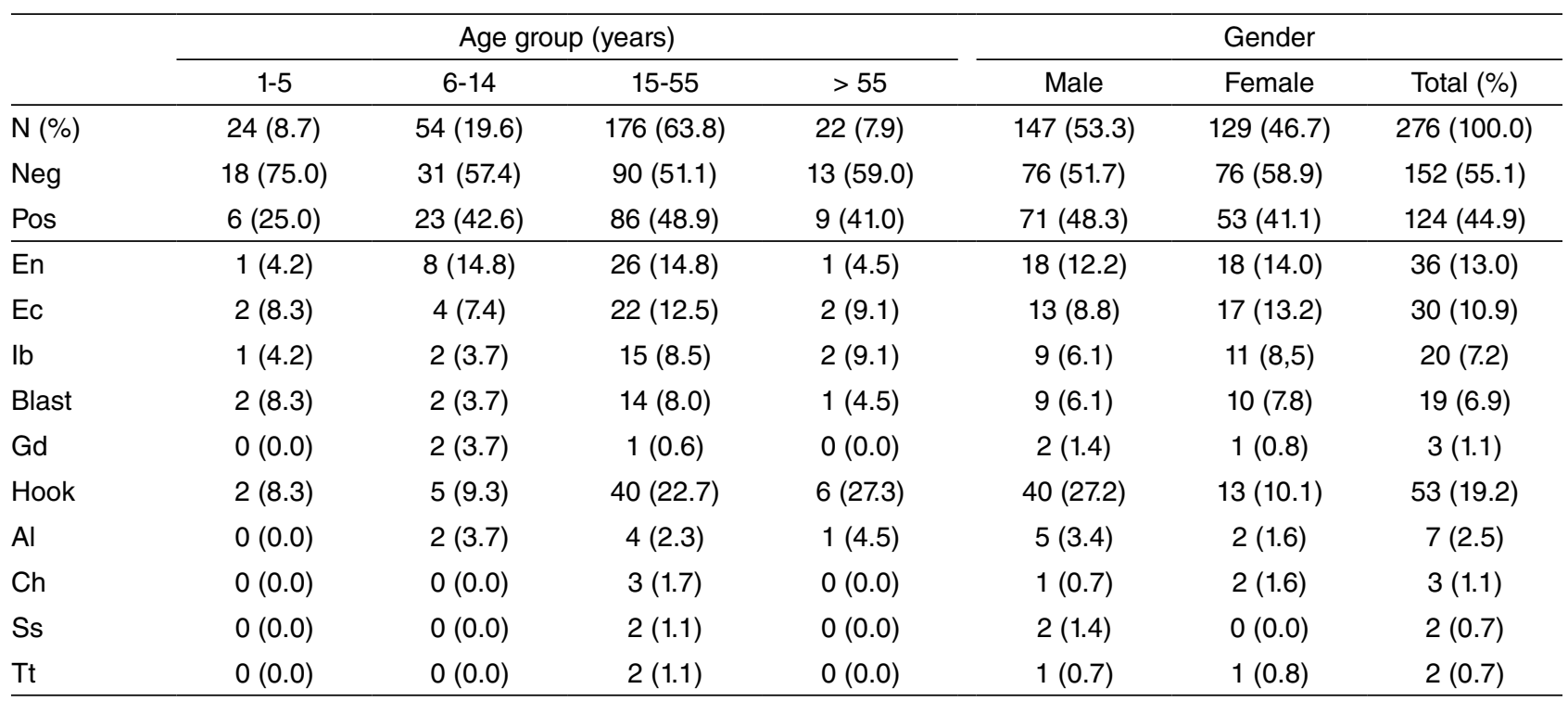

Neg = negative samples; Pos = positive samples; En = Endolimax nana; Ec = Entamoeba coli; Ib = lodamoeba butschlii; Blast = Blastocystis sp; Gd = Giardia duodenalis; Hook = hookworm; $\mathrm{Al}=$ Ascaris lumbricoides; Ch = Calodium hepaticum; $\mathrm{Ss}=$ Strongyloides stercoralis; $\mathrm{Tt}=$ Trichuris trichiura 
the highest positivity rate, followed by Entamoeba coli (10.9\%) (30/276). The prevalence of Blastocystis sp. was $6.9 \%$ (19/276), with greater positivity in adults, but no statistical difference was found when compared to children $(P=0.4270)$. The prevalence of Giardia duodenalis cysts was only $1.1 \%(3 / 276)$.

It is interesting to highlight that helminth eggs found by the Kato-Katz technique were hookworm, $C$. hepaticum, Asacaris lumbricoides and Trichuris trichiura. These data are included in Table 2 where the results of spontaneous sedimentation were shown.

Calodium hepaticum eggs were found in three of 276 $(1.1 \%)$ stool samples (Table 2). Eggs were characteristically thick-shelled, oval-shaped, and non-protruding with bipolar plugs, yellowish-brown in color with striated shells (Figure 1). The size was $64.0 \pm 2.9 \mu \mathrm{m}$ (length) and $37.5 \pm 1.8 \mu \mathrm{m}$ (width).

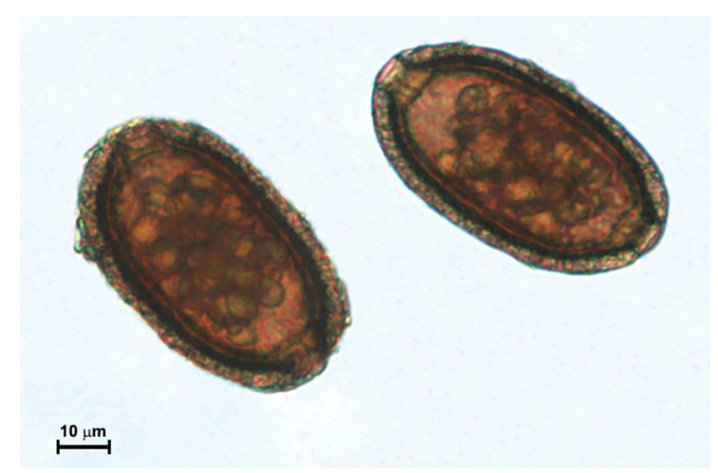

Figure 1 - Eggs of Calodium hepaticum in a fecal sediment obtained through the centrifugation-sedimentation method ${ }^{21}$.

The most common STH was the hookworm (53/276, $19.2 \%)$. The age distribution showed a low prevalence in children aged 1-14 years, an increase in the $15-55$ years age group (40/276, 22.7\%, $P=0.0096)$, and reduction (6/276, $3.4 \%$ ) in the oldest age group ( $>55$ years).

As shown in Table 2, A. lumbricoides (7/276, 2.5\%), T. trichiura (2/276, 0.7\%) and Strongyloides stercoralis $(2 / 276,0.7 \%)$ were the least frequent STHs observed.

\section{DISCUSSION}

Consistent with previous studies carried out in the Western Brazilian Amazon ${ }^{5,9,23-25}$, our parasitological findings revealed that the studied population is exposed to intestinal parasites (protozoa and STHs). This is not surprising given that forest reserve dwellers have no sanitary facilities, practice open defecation near their homes and have no access to clean water. Polyparasitism was less observed than monoparasitism. Similar findings were reported in other communities in Acre State, including Assis
Brasil and Acrelandia ${ }^{18,19}$, as well as in riverside settlements in the Southern Pantanal region (Midwest macro region) ${ }^{26}$.

When considering protozoa transmitted via the fecaloral route, E. nana and E. coli showed higher positive rates, in accordance with previous studies ${ }^{18,19}$. On the other hand, only three stool samples (1.1\%) contained G. duodenalis cysts, in contrast to the high prevalence (19.6\%) among residents from the municipality of Acrelandia (Acre) ${ }^{19}$. Given that $G$. duodenalis excretion can be sporadic in fecal samples, it can be missed if only one sample is examined. In order to overcome this limitation, the examination of multiple fecal samples has been proposed, which reduces the number of false-negative results ${ }^{27}$. However, this can cause logistical problems for the sample collection during fieldwork in rural communities with difficult access, such as Seringal Boa Vista (Xapuri municipality) and Cuidado (Sena Madureira municipality). Furthermore, the prevalence of protozoa may be related to the methodologies employed, since the best technique for detecting cysts and oocysts is the detection by flotation.

Blastocystis sp. is one of the most common enteric protists, reported in both, humans and a wide range of animals of several taxa worldwide ${ }^{28,29}$. However, information regarding its distribution in the Brazilian Amazon is limited. There is substantial heterogeneity between data from Brazilian indigenous populations, ranging from $57.8 \%$ in Oriximina (Para State) ${ }^{30}$ to $20.0 \%$ in Confresa (Mato Grosso State) ${ }^{31}$. In Amazonas State, individuals living in rural areas, such as Santa Isabel do Rio Negro, show a higher prevalence $(10.2 \%)^{32}$ compared to that $(0.7 \%)$ of urban residents living in the Amazonas State capital, Manaus ${ }^{23}$. To the best of our knowledge, this is the first report of Blastocystis sp. in Acre. Forest dwellers have two risk factors for acquiring Blastocystis sp. infection. Firstly, they live in poor social and environmental conditions that facilitate the transmission of parasites via the fecal-oral route $^{19}$. Secondly, Blastocystis sp. is capable of infecting a broad range of hosts, including pets, synanthropic and wild animals ${ }^{29}$. Local residents are in close contact with all of these animals.

Out of 138 cases of spurious infections reported in the literature ${ }^{7}, 93$ were in Brazil, suggesting that $C$. hepaticum can be categorized as a foodborne parasite in the country. We found that $C$. hepaticum eggs were released by a 45 -year-old woman from Xapuri and a 27-year-old woman and her 12-year-old son from Sena Madureira, and all of them were riverine residents (Caete River). We next investigated a possible source of infection. Wild game meat is a major protein source of forest-dwelling populations ${ }^{15}$. During the hunting activity, men stay in the forest for 1-2 days, where larger animals, such as red brocket deer (Mazama 
americana), lowland tapir (Tapirus terrestris) and collared peccary (Pecari tajacu) are eviscerated on the spot, while smaller animals are eviscerated only after returning home.

This eating behavior can pose a threat to these human populations. Previous studies have reported that individuals can develop $C$. hepaticum spurious infections by consuming raw or undercooked livers from wild hosts, both in Amazonian and Southern Brazilian communities ${ }^{4-6,13,14}$. In the present study, all the families reported eating whitelipped peccary, capybara (Hydrochoerus hydrochaeris) and lowland paca. Although $C$. hepaticum infects whitelipped peccary in the Brazilian Amazon ${ }^{5,6,13}$, this finding has never been reported in Acre. In addition, capybaras can serves as hosts of Capillaria hydrochoeri, adult worms are gastrointestinal parasites and eggs released along with host feces show distinct morphometric traits in comparison with $C$. hepaticum ${ }^{33}$. In spite of the fact that $C$. hepaticum eggs show morphometric differences according to different microenvironments (liver from different hosts or feces) $)^{4,5,14,34}$, we confirmed this species identification on the basis of morphological and morphometric determination of $100 \mathrm{eggs}^{5}$. In Acre, it seems more likely that people get infected by eating paca meat ${ }^{15}$. Moreover, a traditional local recipe is prepared from undercooked livers, suggesting that this cultural dietary habit can be the source of $C$. hepaticum infections in local residents. This result is consistent with our previous publication, which for the first time revealed the presence of $C$. hepaticum in liver tissues of a paca trapped in the municipality of Bujari (Acre) ${ }^{16}$.

Over the last decade, a few studies have identified the prevalence of STHs in the North region of Brazil. In this study, the most common STH was the hookworm, confirming previous findings in Acrelandia ${ }^{19}$. Regarding their distribution according to age and gender, children aged 1-14 years showed a lower prevalence when compared to participants aged $15-55$ years $(40 / 276,22.7 \%)$. Given that hookworms are skin-invading nematodes, it is likely that children are predisposed to hookworm infections due to the habit of walking barefoot ${ }^{35}$. Our results for the 15-55 age group showed that males had a roughly three-fold higher risk $(27.2 \%)$ than females $(10.1 \%)$ for acquiring hookworm infections. It is likely that men are more exposed to hookworm infections due to the traditional labor division in which they have agricultural, cattle raising and hunting activities, while women play mainly domestic roles ${ }^{36}$. Obviously, the habit of walking barefoot cannot be excluded among women.

Studies from various municipalities in Amazonas State have demonstrated high prevalence rates of $A$. lumbricoides and T. trichiura ${ }^{23,24}$. As shown in Table 2, both STHs showed low prevalences: $2.5 \%$ of A. lumbricoides and $0.7 \%$ of T. trichiura. This finding is similar to data from Acrelandia ${ }^{13}$.
On the other hand, a recent nationwide population-based sample of school-aged children (7-17 years) showed higher prevalence $(19.14 \%)$ of A. lumbricoides than other geohelminths ${ }^{37}$. Moreover, this finding is against the expectation that A. lumbricoides is the most prevalent STH in Acre. One possible explanation is a mass preventive deworming through the administration of albendazole and mebendazole, periodically. While the etiological treatment strategy reduces the prevalence of helminths, the presence of intestinal protozoa could remain stable or even increase ${ }^{38}$.

There is little consensus on the prevalence rates of S. stercoralis in Latin America ${ }^{39}$. In the Brazilian Amazon, it ranges between $5.6 \%$ (Santa Isabel do Rio Negro, Amazonas State) $)^{32}$ and $2.6 \%$ (Acrelandia) $^{18}$. In our survey, only 2 of 276 stool samples $(0.7 \%)$ were positive for $S$. stercoralis. It is likely that both, the spontaneous sedimentation and the centrifugal sedimentation techniques are insensitive for detecting S. stercoralis in stool samples. Furthermore, there is also intermittent and scanty excretion of larvae in stool specimens ${ }^{40}$. In order to overcome these limitations in the fieldwork, the use of more appropriate methods, such as the Baermann-Moraes and the examination of consecutive samples, has been suggested ${ }^{31,40}$.

\section{Limitations and perspectives}

Our study had limitations. As previously noted, both G. duodenalis and S. stercoralis show a day-to-day variability in the excretion of cysts and larvae, which could have influenced our results. Examination of multiple fecal samples with or without preservative solution could overcome this limitation. However, this procedure has drawbacks in remote rural communities such as the lack of rural electrification or even fuel-powered electric generators, preventing the need of refrigerators for preserving fecal samples. Moreover, many people live in dwellings located along unpaved roads within the forest, making travel to laboratories for parasitological examination difficult. Indeed, road access can be completely blocked during the rainy season (December to May). It is clear that further research will be necessary to gain insight into the possible role of humans, animals or both in G. duodenalis and Blastocystis sp. transmission in Acre State.

\section{CONCLUSION}

Our findings, for the first time, provide some evidence that $C$. hepaticum is a spurious parasite in Acre State. The forest reserve dwellers surveyed probably become infected by consuming undercooked liver of pacas. Their precarious sanitary conditions likely explain the finding 
of soil-transmitted helminths and intestinal protozoa. Hookworm eggs were the most common finding in stool samples. Finally, the presence of Blastocystis sp. in Acre State is reported here for the first time.

\section{AUTHORS' CONTRIBUTIONS}

FBO, RRS and JRMS designed the experiments; FBO, TPDC, LBN, PEFT, JCM and LSS; FBO, TPDC and LBN performed the experiments; FBO and LBN obtained and anlyzed the data; RHN performed statistical analysis; MNB provided medical care to the participants of this study; FBO wrote the manuscript; FBA, RRS and JRMS revised the manuscript. All authors read and approved the final version.

\section{REFERENCES}

1. Fuehrer HP. An overview on the host spectrum and distribution of Calodium hepaticum (syn. Capillaria hepatica): part 1Muroidea. Parasitol Res. 2014;113:619-40.

2. Ochi A, Hifumi T, Ueno T, Katayama Y. Capillaria hepatica (Calodium hepaticum) infection in a horse: a case report. BMC Vet Res. 2017;13:384.

3. Galán-Puchades MT, Sanxis-Furió J, Pascual J, Bueno-Marí R, Franco S, Peracho V, et al. First survey on zoonotic helminthosis in urban brown rats (Rattus norvegicus) in Spain and associated public health considerations. Vet Parasitol. 2018;259:49-52.

4. Carvalho-Costa FA, Silva AG, Souza AH, Moreira CJ, Souza DL, Valverde JG, et al. Pseudoparasitism by Calodium hepaticum (syn. Capillaria hepatica; Hepaticola hepatica) in the Negro River, Brazilian Amazon. Trans R Soc Trop Med Hyg. 2009;103:1071-3.

5. Soares MC, Nunes HM, Silveira FA, Alves MM, Souza AJ. Capillaria hepatica (Bancroft, 1893) (Nematoda) entre populações indígenas e mamíferos silvestres no noroeste do Estado do Mato Grosso, Brasil, 2000. Rev Pan-Amaz Saude. 2011;2:35-40.

6. Gonçalves AQ, Ascaso C, Santos I, Serra PT, Julião GR, Orlandi PP. Calodium hepaticum: household clustering transmission and the finding of a source of human spurious infection in a community of the Amazon region. PLoS Negl Trop Dis. 2012;6:e1943.

7. Fuehrer HP, Igel P, Auer H. Capillaria hepatica in man: an overview of hepatic capillariosis and spurious infections. Parasitol Res. 2011;109:969-79.

8. Coimbra Jr. CE, Mello DA. Enteroparasitas e Capillaria sp. entre o grupo Suruí, Parque Indígena de Aripuanã, Rondônia. Mem Inst Oswaldo Cruz. 1981;76:299-302.

9. Santos RV, Coimbra Jr CE, Ott AM. Estudos epidemiológicos entre grupos indígenas de Rondônia. III. Parasitoses intestinais nas populações dos vales dos rios Guaporé e Mamoré. Cad Saude Publica. 1985;1:467-77.

10. Santos RV, Coimbra Jr CE, Flowers NM, Silva JP. Intestinal parasitism in the Xavánte Indians, Central Brazil. Rev Inst Med Trop Sao Paulo. 1995;37:145-8.

11. Machado ER, Santos DS, Costa-Cruz JM. Enteroparasites and commensals among children in four peripheral districts of Uberlândia, state of Minas Gerais. Rev Soc Bras Med Trop. 2008;41:581-5.

12. Palhano-Silva CS, Araújo AJ, Lourenço AE, Bastos ON, Santos $\mathrm{RV}$, Coimbra Jr CE. Intestinal parasitic infection in the Suruí Índians, Brazilian Amazon. Interciencia. 2009;34:259-64.

13. Camargo LM, Camargo JS, Vera LJ, Barreto PT, Tourinho EK, Souza MM. Capillariasis (Trichurida, Trichinellidae, Capillaria hepatica) in the Brazilian Amazon: low pathogenicity, low infectivity and a novel mode of transmission. Parasit Vectors. 2010;3:11

14. Klisiowicz DR, Reifur L, Shimada MK, Haidamak J, Cognialli RC, Ferreira T. High occurrence of Calodium hepaticum (syn. Capillaria hepatica) spurious infection in a village in the Atlantic Forest of southern Brazil. Mem Inst Oswaldo Cruz. 2014;109:371-3.

15. Valsecchi J, El Bizri HR, Figueira JE. Subsistence hunting of Cuniculus paca in the middle of the Solimões River, Amazonas, Brazil. Braz J Biol. 2014;74:560-8.

16. Almeida F, Caldas R, Corrêa C, Rodrigues-Silva R, Siqueira N, Machado-Silva JR. Co-infections of the cestode Echinococcus vogeli and the nematode Calodium hepaticum in the hystricomorphic rodent Agouti paca from a forest reserve in Acre, Brazil. J Helminthol. 2013;87:489-93.

17. World Health Organization. Soil-transmitted helminth infections. [cited 2021 Jun 24]. Available from: https://www.who.int/ news-room/fact-sheets/detail/soil-transmitted-helminthinfections

18. Muniz PT, Castro TG, Araújo TS, Nunes NB, Silva-Nunes MD, Hoffmann EH, et al. Child health and nutrition in the Western Brazilian Amazon: population-based surveys in two counties in Acre State. Cad Saude Publica. 2007;23:1283-93.

19. Souza EA, Silva-Nunes M, Malafronte RS, Muniz PT, Cardoso MA, Ferreira UM. Prevalence and spatial distribution of intestinal parasitic infections in a rural Amazonian settlement, Acre State, Brazil. Cad Saude Publica. 2007;23:427-34.

20. Hoffmann WA, Pons JA, Janer JL. Sedimentation concentration method in schistosomiasis. Puerto Rico J Public Health. 1934;9:283-9.

21. Blagg W, Schloegel EL, Mansur NS, kholaf GL. A new concentration technic for the demonstration of protozoa and helminth eggs in feces. Am J Trop Med Hyg. 1955;4:23-8.

22. Katz N, Chaves A, Pellegrino J. A simple device for quantitative stool thick-smear technique in schistosomiasis mansoni. Rev Inst Med Trop Sao Paulo. 1972;14:397-400. 
23. Visser S, Giatti LL, Carvalho RA, Guerreiro JC. Estudo da associação entre fatores socioambientais e prevalência de parasitose intestinal em área periférica da cidade de Manaus (AM, Brasil). Cien Saude Colet. 2011;16:3481-92.

24. Gonçalves AQ, Junqueira AC, Abellana R, Barrio PC, Terrazas WC, Sodré FC, et al. Prevalence of intestinal parasites and risk factors for specific and multiple helminth infections in a remote city of the Brazilian Amazon. Rev Soc Bras Med Trop. 2016;49:119-24.

25. Marques RC, Bernardi JV, Dorea CC, Dórea JG. Intestinal parasites, anemia and nutritional status in young children from transitioning Western Amazon. Int J Environ Res Public Health. 2020;17:577.

26. Silva PV, Maciel LS, Castro LS, Murat PG, Higa Junior MG, Zerlotti PH, et al. Enteroparasites in riverside settlements in the Pantanal wetlands ecosystem. J Parasitol Res. 2018;2018: 6839745.

27. Uchôa FF, Sudré AP, Campos SD, Almosny NR. Assessment of the diagnostic performance of four methods for the detection of Giardia duodenalis in fecal samples from human, canine and feline carriers. J Microbiol Methods. 2018;145:73-8.

28. Skotarczak B. Genetic diversity and pathogenicity of Blastocystis. Ann Agric Environ Med. 2018;25:411-6.

29. Zanetti AD, Malheiros AF, Matos TA, Longhi FG, Moreira LM, Silva SL, et al. Prevalence of Blastocystis sp. infection in several hosts in Brazil: a systematic review and meta-analysis. Parasit Vectors. 2020;13:30.

30. Borges JD, Alarcón RS, Amato Neto V, Gakiya E. Parasitoses intestinais de indígenas da comunidade Mapuera (Oriximiná, Estado do Pará, Brasil): elevada prevalência de Blastocystis hominis e encontro de Cryptosporidium sp e Cyclospora cayetanensis. Rev Soc Bras Med Trop. 2009;42:348-50.

31. Malheiros AF, Stensvold CR, Clark CG, Braga GB, Shaw JJ Molecular characterization of Blastocystis obtained from members of the indigenous Tapirapé ethnic group from the Brazilian Amazon region, Brazil. Am J Trop Med Hyg. 2011;85:1050-3.
32. Valverde JG, Gomes-Silva A, De Carvalho Moreira CJ, Leles de Souza D, Jaeger LH, Martins PP, et al. Prevalence and epidemiology of intestinal parasitism, as revealed by three distinct techniques in an endemic area in the Brazilian Amazon. Am J Trop Med Hyg. 2011;105:413-24.

33. Sinkoc AL, Brum FA, Muller G, Brum JG. Helmintos parasitos de capivara (Hydrochoerus hydrochaeris L. 1766) na região de Araçatuba, São Paulo, Brasil. Arq Inst Biol. 2004;71:329-33.

34. Borba VH, Machado-Silva JR, Le Bailly M, Iñiguez AM. Worldwide paleodistribution of capillariid parasites: Paleoparasitology, current status of phylogeny and taxonomic perspectives. PLoS One. 2019;14:e0216150.

35. Haldeman MS, Nolan MS, Ng'habi KR. Human hookworm infection: is effective control possible? A review of hookworm control efforts and future directions. Acta Trop. 2020;201:105214.

36. Sardenberg C, Costa AA, Passos E. Rural development in Brazil: are we practising feminism or gender? Gend Dev. 1999;7:2838.

37. Katz N. Inquérito nacional de prevalência da esquistossomose mansoni e geo-helmintoses. Belo Horizonte: Fundação Oswaldo Cruz; 2018.

38. Oliveira YL, Oliveira LM, Oliveira YL, Nascimento AM, La Corte $\mathrm{R}$, et al. Changes in the epidemiological profile of intestinal parasites after a school-based large-scale treatment for soil-transmitted helminths in a community in northeastern Brazil: epidemiological profile after large-scale school-based treatment for STH. Acta Trop. 2020;202:105279.

39. Buonfrate D, Mena MA, Angheben A, Requena-Mendez A, Muñoz J, Gobbi F, et al. Prevalence of strongyloidiasis in Latin America: a systematic review of the literature. Epidemiol Infect. 2015;143:452-60

40. Nutman TB. Human infection with Strongyloides stercoralis and other related Strongyloides species. Parasitology. 2017;144:263-73 